A CALCIUM OXIDE SORBENT PROCESS

$\mathrm{DOE} / \mathrm{MC} / 26366--3233$

FOR BULK SEPARATION OF CARBON DIOXIDE

DE93 007549

\title{
FIECEIVED
}

FEB 161993

Contract No. DE-AC21-89MC26366

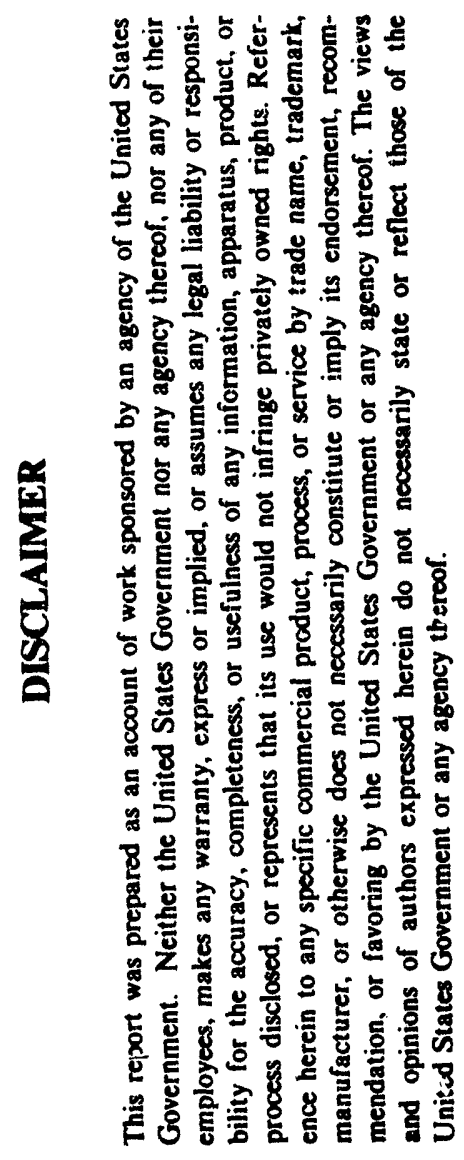

\author{
Quarterly Progress Report 11 \\ April 1992 - June 1992 \\ Department of Chemical Engineering \\ Louisiana State University \\ Baton Rouge, Louisiana 70803 \\ (504) 388-1426
}

Douglas P. Harrison

1 Principal Investigator

August 1992 
EXECUTIVE SUMMARY

This research project is investigating the technical feasibility of a high-temperature, high-pressure (HTHP) process for the bulk separation of $\mathrm{CO}_{2}$ from coal-derived gas. The original two-year contract was awarded in september 1989 as a result of solicitation number DE-RA2198MC26040 entitled "Novel Concepts for Bulk Separation of Gases in Coal Gasification systems". Two no-cost extensions without a change in statement of work extended the performance period by six months to March 1992. At that time a two-year contract extension with an enlarged scope of work and additional runding was approved so that the contract is now due to end in March 1994.

Phase I research, which utilized an electrobalance reactor, was completed duxing the previous quarter and final experimental results have been reported. Phase II research involves a switch from the electrobalance reactor to a laboratory-scale fixed-bed reactor having feed and product gas analysis caplability. Initial effort during Phase II has been limited to project planning including the design and construction of the fixed-bed reactor, developing specifications for gas analysis, and ordering the gas chromatograph system. These activities are described in the present report.

\section{FIXED-BED REACTOR}

A diagram of the fixed-bed reactor system currently being constructed is shown in Figure 1 . The synthetic coal-gas mixture (sulfur-free) will be obtained from high-pressure cylinders of $\mathrm{CO}_{2}, \mathrm{CO}$, $\mathrm{H}_{2}$, and $\mathrm{N}_{2}$. Two $\mathrm{N}_{2}$ cylinders will be used so that calcination can occur at the same time that the reactor feed composition is being adjusted and 
by-passed to vent. After initial pressure regulation at the cylinder, each gas will flow, in turn, through a filter, a high-pressure mass flow controller, and a check valve. Aitar the permanent gases are mixed, water will be added from a high-pressure syringe pump. Appropriate feed lines will be heat traced, first to insure vaporization of the water as it mixes with the permanent gases, and later to prevent water condensation in feed and exit lines. Much of the feed system, including the high pressure syringe purmp and four of the five mass flow controllers were used in the Phase I research. An additional mass flow controller was purchased for the fixed-bed research in order to have greater flexibility in the composition and flow rate of the reactor feed.

Feed gases will enter near the bottom of the reactor and flow upward in the annular space between the pressure vessel and he reactor insert tube. Gas preheating will be accomplished in this annular section. Preheated gases will then flow downward through the sorbent where reaction will occur. Finally, product gas will exit from the bottom of the reactor through a condenser, a filter, and a back-pressure regulator. A sample of either the by-passed reactor feed or product gas can be removed for gas chromatographic analysis.

During the calcination cycle only nitrogen will be fed to the reactor. The calcination product gas can be sampled and analyzed for $\mathrm{CO}_{2}$ concentration to determine when calcination is complete. While calcination is occurring, the carbonation gas composition and flow rate will be adjusted and allowed to flow through the reactor by-pass line. The by-pass line contains an identical condenser, filter, and backpressure regulator to that in the reactor product line. The by-passed 
feed gas may also be sampled and analyzed by gas chromatography. The condenser, filter, pressure indicator, and back-pressure regulator arrangements are also the same as used in the Phase I electrobalance studies.

The reactor will be heated using a split-tube furnace (Applied Test Systems Series 3210) equipped with a single-zone temperature controller which is microprocessor programmable for up to eight ramp and soak intervals. An over-temperature controller provides protection against temperature run-away. This is the same furnance and temperature controller used in the Phase I study.

The fixed-bed reactor was designed and is being constructed at LSU. A detailed diagram is shown in Figure 2. Feed gases will enter near the bottom and flow upward in the annular space between the pressure vessei and the reactor inlet tube. In this section the feed gases will be preheated directly by the furnace and by exchange with the reacting and product gases. After emerging from the annular preheat section, the feed gases will flow downward inside the reactor insert over four separate sorbent sections. Product gases will exit the system from the side of the pressure plug at the bottom of the reactor. A $1 / 4$ inch outside diameter thermowell containing six axially spaced thermocouples will pass through the pressure plug and up the center of the reactor insert. The thermocouple spacing will permit measurement of the temperature of the preheated feed gases (TC1), at the center of each of the four sorbent sections (TC2, TC3, TC4, TC5), and of the product gas after heat exchange with the feed gas (TC6).

The pressure seal will be at the bottom of the reactor with separate "O-ring" seals between the pressure vessel and the top lip of 
the insert tube, and between the bottom lip of the insert tube and the pressure plug. This pressure seal is similar to that employed in the Phase I study using the high pressure electrobalance.

Each of the four sorbent sections will be separated by a porous stainless steel disc which fits over the thermowell and inside the reactor insert. Separating the sorbent into the four sections will permit easier characterization of the sorbent as a function of axial position at the end of a test.

Reactor performance will be time dependent as sorbent within the reactor is converted. An idealized diagram of the $\mathrm{CO}_{2}$ concentration as a function of axial position during a carbonation cycle is shown in Figure 3a. Near the beginning of a cycle at $t_{1}$, carbonation will occur near the reactor entrance, and the $\mathrm{CO}_{2}$ concentration will be reduced to its equilibrium value some distance from the inlet. Sorbent near the entrance will soon become exhausted, and at time $t_{2}$ the position of the reaction front will shift away from the entrance. After sufficient time $\left(t_{3}\right)$ the leading edge of the reaction front will correspond to the reactor exit position and $\mathrm{CO}_{2}$ breakthrough will occur. The idealized $\mathrm{CO}_{2}$ breakthrough curve, concentration of $\mathrm{CO}_{2}$ in the reactor product as a function of time, is shown in Figure $3 \mathrm{~b}$. For $t<t_{3}$, the $\mathrm{CO}_{2}$ exit concentration will be near zero (or its equilibrium value). The exit concentration of $\mathrm{CO}_{2}$ will begin to increase at $t_{3}$, and if the reaction is permitted to continue, all of the sorbent will be exhausted and the inlet and exit $\mathrm{CO}_{2}$ concentrations will become equal at $t_{4}$.

Carbonation is an exothermic reaction and the progress of the reaction can be followed qualitatively by following the movement of the temperature front through the reactor. An idealized response of each of 
the thermocouples as a function of time is shown in Figure 3c. The thermocouple nearest the reactor entrance (TC2) should see the highest overall temperature and the sharpest temperature front. As the temperature front progresses through the reactor, the maximum temperature should decrease and the temperature front should become broader.

During the endothermic calcination reaction, the shape of the curves should be reversed. $\mathrm{CO}_{2}$ becomes a reaction product and complete calcination will correspond to zero $\mathrm{CO}_{2}$ concentration in the exit gas. The thermocouples will measure temperature decreases.

\section{GAS ANALYSIS}

Feed and product gas composition will be determined by gas chromatography. A Shimadzu model GC-14A chromatograph equipped with thermal conductivity (TCD) and flame ionization (FID) detectors, a nickel-catalyzed methanizer, and high-temperature multi-port switching valves has been ordered. Hyrodrogen analysis as well as $\mathrm{CO}$ and $\mathrm{CO}_{2}$ analysis at high concentration will utilize the TCD. At lower concentrations the sensitivity of the $\mathrm{TCD}$ for $\mathrm{CO}$ and $\mathrm{CO}_{2}$ may not be satisfactory. In these situations, both $\mathrm{CO}$ and $\mathrm{CO}_{2}$ will be converted to $\mathrm{CH}_{4}$ in the methanizer and low concentration analysis will be accomplished using the FID.

Current plans call for the installation of four-port, ten-port, and six-port high-temperature sampling valves so that both the reactor feed and product gases can be automatically sampled and the key components can be separated. Three columns will be required for the analysis. The first column, Hayesep 2, will separate the remaining water vapor which escapes the condenser from the permanent gases. Permanent gases will 
pass to the second column, Hayesep 1, while water is back flushed from HayeSep 1 and vented from the system. $\mathrm{CO}_{2}$ is retained on Hayesep 1 while $\mathrm{CO}$ and $\mathrm{H}_{2}$ pass through to the molecular sieve column.

Proper sequencing of the multiport sampling valves will produce ultimate separation of the $\mathrm{H}_{2}, \mathrm{CO}$, and $\mathrm{CO}_{2}$. Column effluents will pass in series through the thermal conductivity detector, the nickel-catalyst methanizer, and the flame ionization detector. Hydrogen will be added between the TDC and methanizer to promote the conversion of $\mathrm{CO}$ and $\mathrm{CO}_{2}$ to $\mathrm{CH}_{4}$. Air will then be added to the FID to achieve complete combustion of the $\mathrm{CH}_{4}$ to $\mathrm{CO}_{2}$. TDC output will be used for analysis of $\mathrm{H}_{2}$ and for high concentrations of $\mathrm{CO}$ and $\mathrm{CO}_{2}$. FID output will be used for low $\mathrm{CO}$ and $\mathrm{CO}_{2}$ concentrations where the TCD is not sufficiently sensitive. 


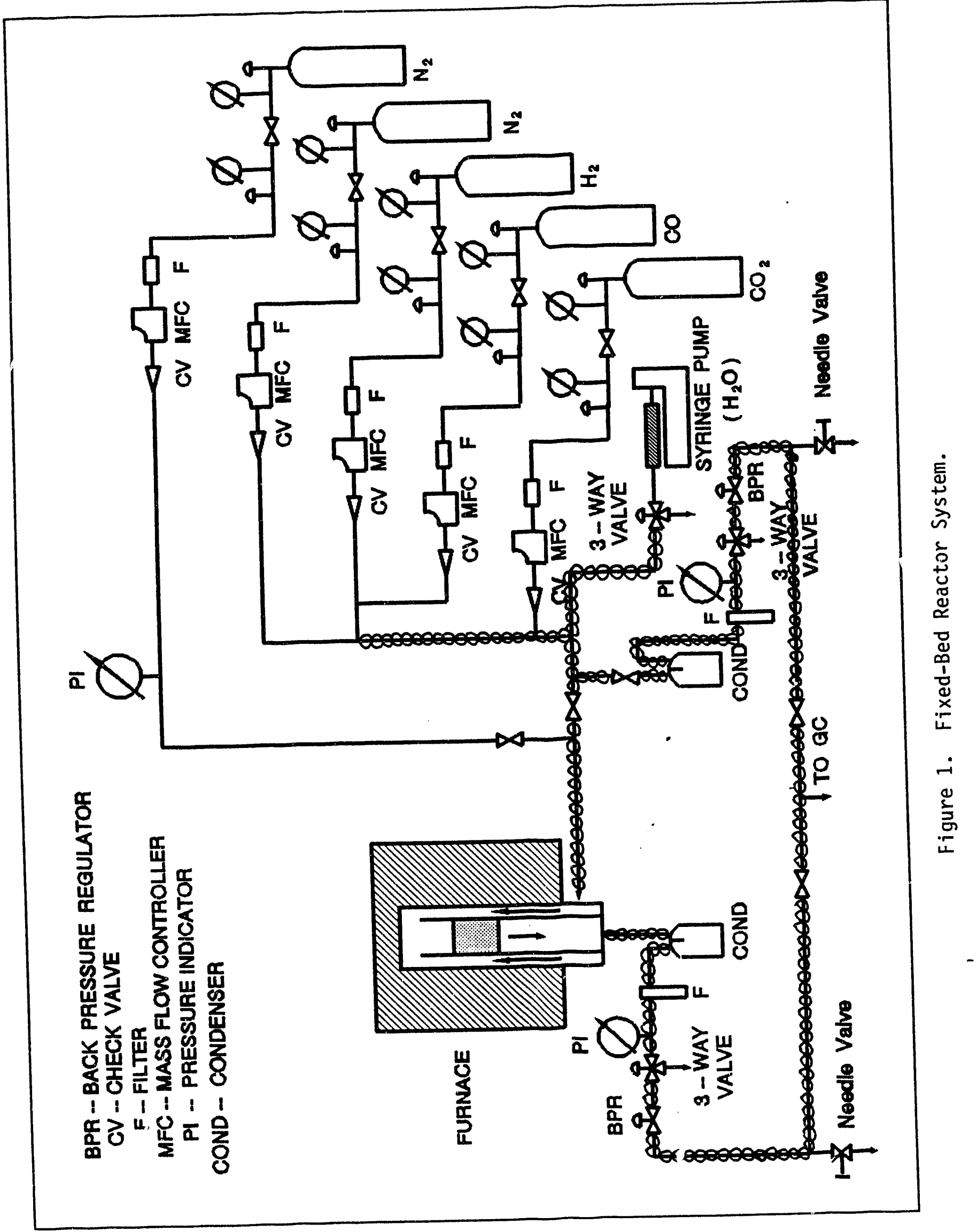




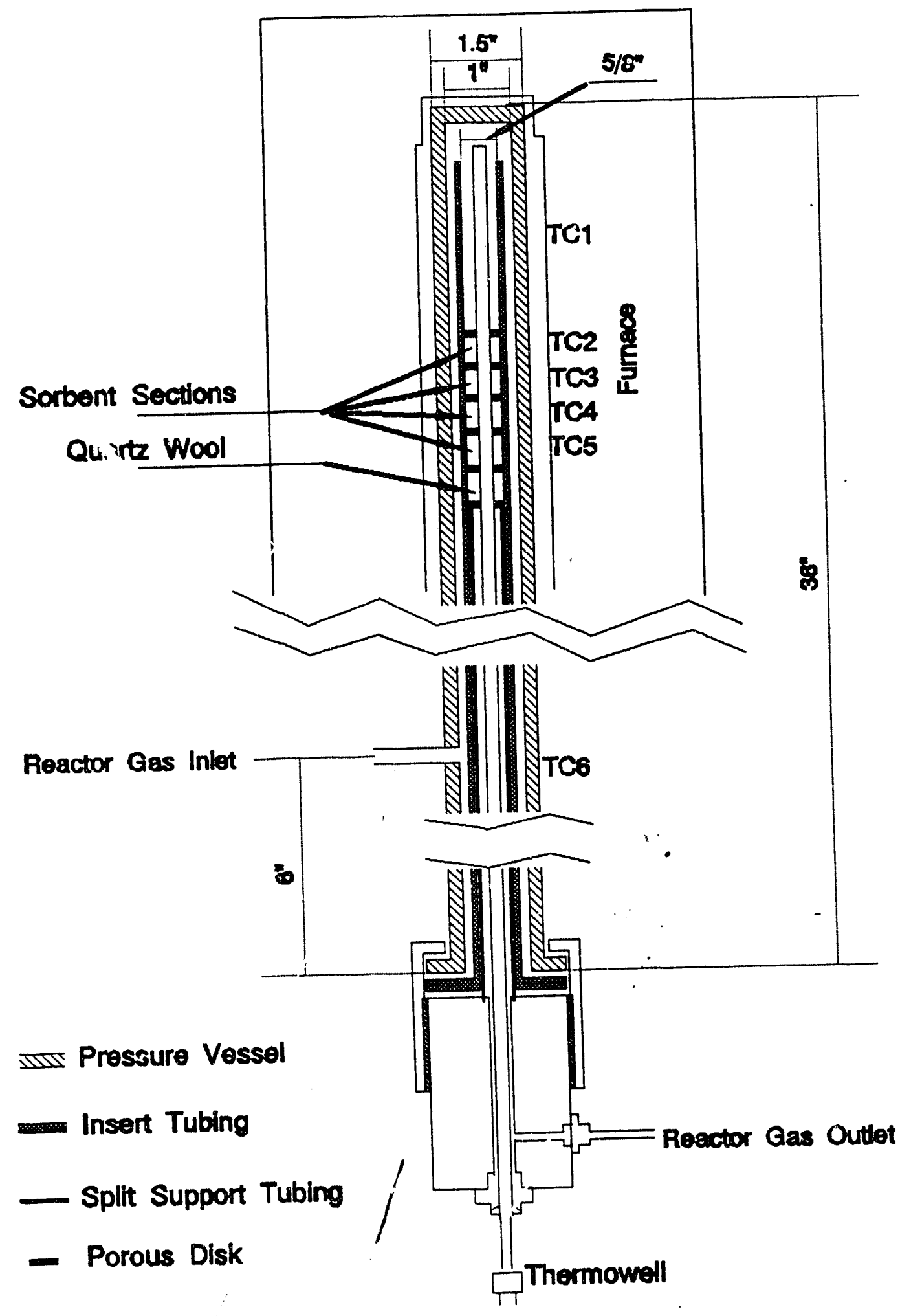

Reactor System

Figure 2. Detailed View of the Fixed-Bed Reactor. 

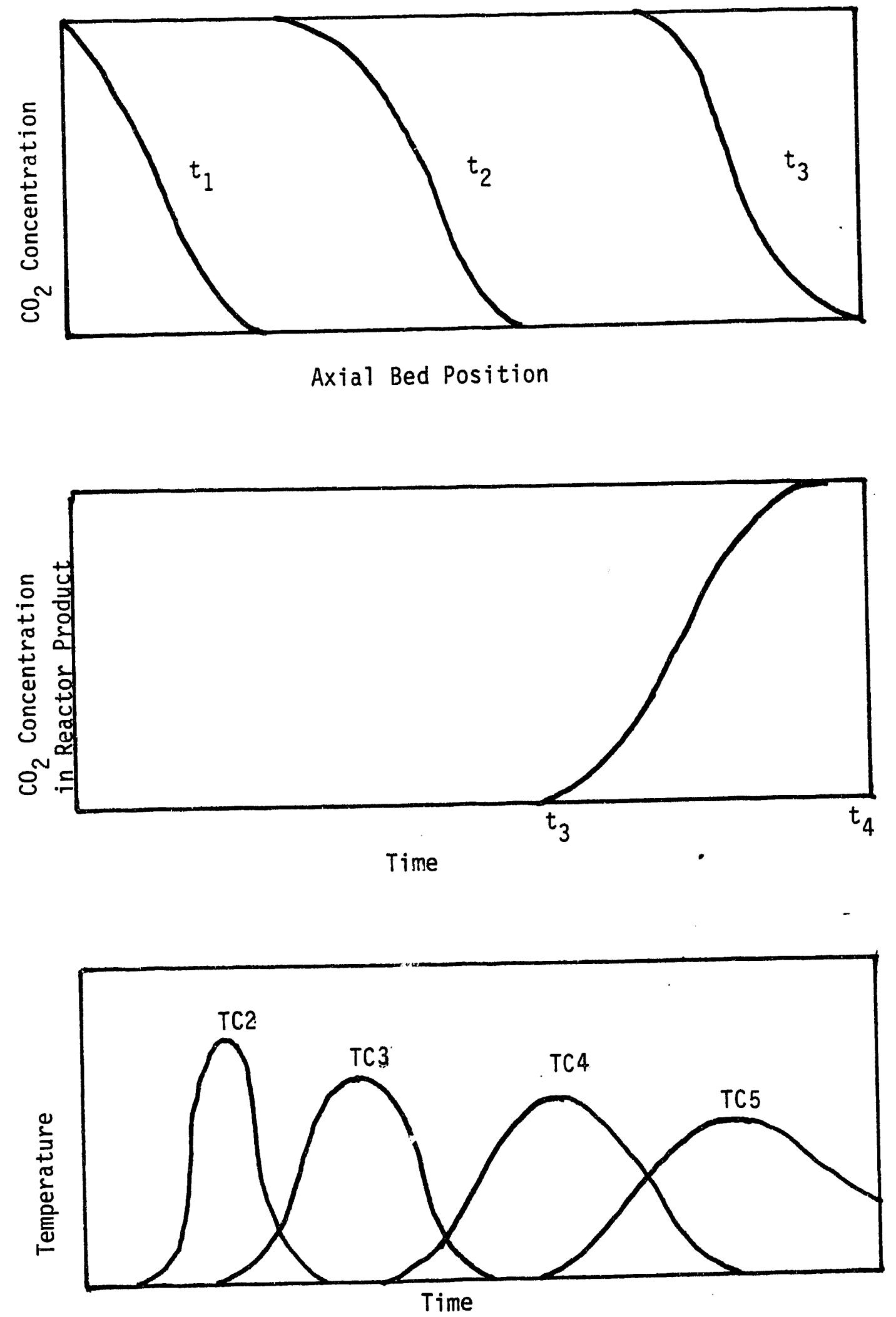

Figure 3. Idealized Fixed-Bed Reactor Response. 
$y$
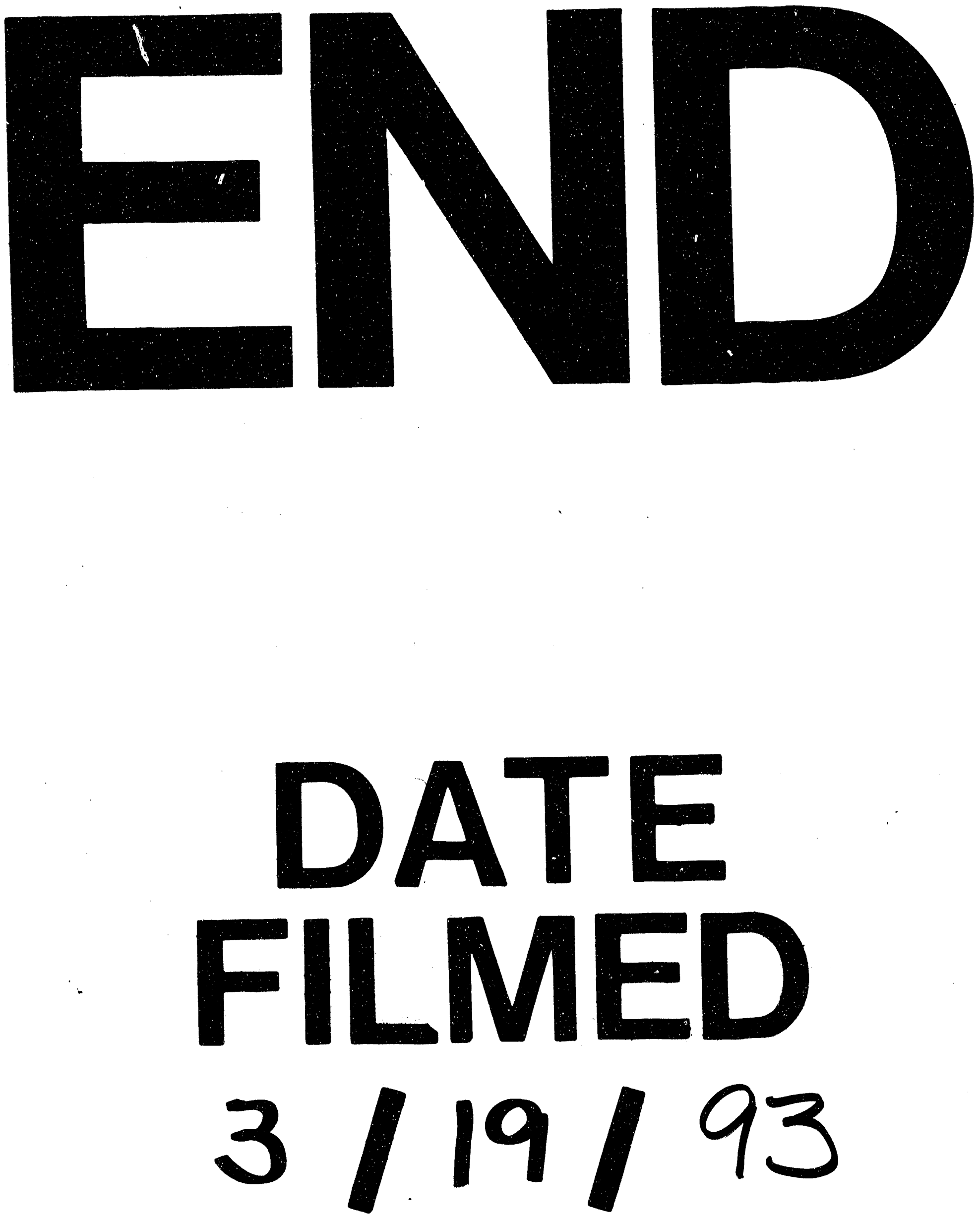
